\title{
O MODELO PROCESSUAL COOPERATIVO E A FLEXIBILIZAÇÃO PROCEDIMENTAL ${ }^{1}$
}

\section{THE COOPERATIVE PROCESS MODEL AND PROCEDURAL FLEXIBILIZATION}

Luiz R. Wambier

Doutor em Direito pela Pontifícia Universidade Católica de São Paulo (PUC-SP). Professor no programa de mestrado em Direito do Instituto Brasiliense de Direito Público (IDP). Membro efetivo do Instituto dos Advogados Brasileiros (IAB). Membro honorário da Associação Brasiliense de Direito Processual Civil (ABPC). Membro da Associação Brasileira de Direito Processual (ABDPro). Membro do Conselho Consultivo da Câmara de Arbitragem da Federação das Indústrias do Paraná (CAMFIEP) e da Câmara de Mediação e Arbitragem da Sociedade Rural Brasileira (CARB). Advogado. Ponta Grossa/PR. luiz.wambier@wambier.com.br

RESUMO: O legislador do Código de Processo Civil de 2015, atento aos contornos da sociedade contemporânea, introduziu no sistema brasileiro mecanismos de maior adequação para o tratamento dos conflitos atuais. Dentre eles, merece especial destaque a flexibilização procedimental, desenvolvida a partir da percepção de que a anterior rigidez formal na condução do processo já não se mostrava capaz de lidar com as novas demandas, e o modelo cooperativo de processo, caracterizado pelo redimensionamento da atuação do juiz e da sua relação com as partes. O presente artigo volta-se à análise desses mecanismos e da compatibilização deles com as demais garantias fundamentais do processo.

PALAVRAS-CHAVE: Novo Código de Processo Civil - Flexibilização procedimental Dever de cooperação - Garantias constitucionais do processo.

\footnotetext{
${ }^{1}$ Artigo recebido em 10/10/2017, sob dispensa de revisão.
} 


\begin{abstract}
The legislator of the Civil Procedure Code of 2015, attentive to the contours of contemporary society, introduced in the Brazilian system mechanisms of greater adequacy for the treatment of the current conflicts. Among them, procedural flexibility deserves special emphasis, developed from the perspective that the previous formal rigidity in the conduction of the process was no longer able to deal with the new demands, and the cooperative process, characterized by the new dimensioning of the judge's performance and his relationship with the parties. The present article is directed to the analysis of these mechanisms and their compatibility with the other process fundamental guarantees.
\end{abstract}

KEYWORDS: New Civil Procedure Code - Procedural flexibilization - Duty of cooperation - Constitutional guarantees of the process.

SUMÁRIO: 1. Introdução. 2. Noções elementares da flexibilização procedimental. 3. Aspectos práticos da flexibilização procedimental no novo CPC. 4. O devido processo legal e a segurança jurídica. 5. O modelo cooperativo de processo. 6. Considerações finais.

SUMMARY: 1. Introduction. 2. Elementary notions of procedural flexibilization. 3. Practical aspects of procedural flexibilization in the new Civil Procedure Code. 4. The due process of law and legal certainty. 5. The cooperative process model. 6. Final considerations.

\title{
1. Introdução
}

Define-se procedimento como o modo de ser do processo, ou seja, a forma como se desencadeiam os atos processuais, estruturados com vista a um objetivo final, que é a adequada prestação da tutela jurisdicional.

No passado, houve certa confusão entre os conceitos de processo e procedimento, atribuída em grande parte à etimologia da palavra "processo". Procedere, em latim, significa "seguir adiante", o que nos remete à ideia de movimento e à concatenação de atos 
Revista Eletrônica de Direito Processual - REDP.

Rio de Janeiro. Ano 11. Volume 18. Número 3. Setembro a Dezembro de 2017

Periódico Quadrimestral da Pós-Graduação Stricto Sensu em Direito Processual da UERJ

Patrono: José Carlos Barbosa Moreira. ISSN 1982-7636. pp. 238-255

www.redp.uerj.br

processuais (e que se relaciona, na verdade, com o conceito de procedimento, como acima se mencionou, e não de processo). Com o passar do tempo, o conceito de processo foi ganhando novos e mais precisos contornos. Compreendeu-se que processo não significa a forma de organização dos atos processuais, mas que ele se define a partir de sua própria teleologia. Se os fins do processo estão relacionados com a função de solucionar a parcela do conflito de interesses submetida ao Poder Judiciário pela parte, trata-se ele, então, do instrumento estatal de pacificação dos conflitos no Estado de Direito ${ }^{2}$.

$\mathrm{Na}$ verdade, processo e procedimento são diferentes aspectos de um mesmo objeto. $^{3}$ Em geral, o processo de conhecimento tem seu curso através das regras do procedimento comum, que se aplica à maior parte dos pedidos em juízo. O procedimento comum, a que se pode chamar de procedimento padrão, é o que se utiliza no maior número de pretensões de direito material, prestando-se a veicular, perante o Poder Judiciário, pedidos relativos às situações mais comuns, isto é, despidas de especificidades que, a critério do legislador, mereceriam um tratamento diferenciado.

\footnotetext{
${ }^{2}$ A respeito, v. WAMBIER, Luiz Rodrigues; TALAMINI, Eduardo. Curso Avançado de Processo Civil. 16. ed. São Paulo: Revista dos Tribunais, 2016, v. 1, p. 271-273.

${ }^{3}$ Sobre o tema, cf. WAMBIER, Luiz Rodrigues. Liquidação da sentença civil: individual e coletiva. 5. ed. São Paulo: RT, 2013, p. 87: "Como instrumento à disposição das partes, o processo é o meio pelo qual, diante de um conflito de interesses não resolvido, se possa buscar a atuação da jurisdição. Como instrumento do poder estatal, por outro lado, o processo é o mecanismo pelo qual o Estado dá às partes a solução do sistema jurídico para o conflito intersubjetivo. A questão da instrumentalidade do processo diante do Estado de Direito representa, na verdade, uma necessária postura metodológica, que tem auxiliado os processualistas a enxergarem o processo para além de seus elementos intrínsecos, buscando vê-lo como um expressivo mecanismo de realização dos objetivos do próprio Estado de Direito. O procedimento, por seu turno, embora esteja visceralmente unido ao processo, é tão somente o mecanismo, no sentido mais formal da expressão, pelo qual, a teor da escolha legislativa, se operam os processos nas esferas do poder estatal". Ainda (p. 88): "Em nosso entender, se é correto afirmar que o processo é substancialmente a relação jurídica de natureza processual que se instaura entre as partes e o Estado, não é menos veraz reconhecer que o procedimento exerce um papel determinante no processo, na medida em que se revela como seu aspecto formal, ou a sua exteriorização, do ponto de vista de sua organização estrutural. Já se dizia que processo é conteúdo e procedimento é forma. Embora se trate de explicação relativamente simplista, ela contém, na verdade, forte conteúdo, que facilita a compreensão das diferenças entre um e outro conceito. É certo que o procedimento dá a necessária funcionalidade ao processo". Sobre o tema, Teresa Arruda Alvim afirma que: "para a noção de processo, interessam fundamentalmente as ideias de relação jurídica - que é a que se estabelece entre os sujeitos do processo: autor, juiz e réu - e a de finalidade - no sentido de vocação do fluxo dos atos consecutivos e interligados, que porão em movimento a relação já referida, vocação esta que se volta, concretamente, à obtenção de um pronunciamento judicial de caráter definitivo. À concepção da noção de procedimento dizem respeito as noções de movimento dessa relação jurídica no tempo e, mais especificamente, o aspecto exterior desta movimentação, ou seja, de que atos se trata, como se entrelaçam etc. Assim, os dois conceitos se afastam, não por se referirem a objetos diversos, mas por dizerem respeito a aspectos diversos do mesmo objeto e, pois, observáveis na mesma realidade fática" (ALVIM, Teresa Arruda. Nulidades do processo e da sentença. 7. ed. São Paulo: RT, 2014, p. 25).
} 
Já o elenco de procedimentos especiais foi criado pelo legislador tendo em conta as peculiaridades de certas pretensões de direito material, hábeis a justificar, a partir dos critérios eleitos pelo legislador, a obtenção de tratamento procedimental diferenciado. Os critérios de que se terá servido o legislador para eleger os temas de direito material merecedores de especial procedimento quando submetidos ao Poder Judiciário são de diversas ordens: econômicos, políticos, conjunturais, históricos etc. ${ }^{4}$

Certamente, a escolha da matéria possessória, por exemplo, como apta a comportar especial tratamento procedimental, tem como base a escolha política do legislador. O mesmo se pode dizer quanto à ação de exigir contas e assim por diante.

Na nova sistemática processual, o que fez o legislador de 2015, fiel à exposição de motivos do Anteprojeto do Código, foi simplificar a questão procedimental, escolhendo um número menor de procedimentos especiais. Se na vigência do Código anterior havia os procedimentos ordinário, sumário, sumaríssimo (posteriormente confiado à competência dos Juizados Especiais) e mais uma vasta quantidade de procedimentos especiais, no Código atual, a opção do legislador foi a simplificação a partir da adoção de um modelo do procedimento comum, apto a veicular a maior parte dos pedidos postos em juízo, e da escolha de apenas alguns procedimentos especiais, destinados a tutelar situações de direito material para as quais o legislador resolveu conceder tratamento procedimental especial. E há também os procedimentos a que se pode denominar "especialíssimos", originados dos negócios jurídicos processuais, produto de convenção das partes (de modo bilateral e no plano contratual), ou dessas com o juiz, a exemplo da "calendarização processual", prevista no art. 191 do CPC, de que adiante se tratará.

\section{Noções elementares da flexibilização procedimental}

É possível definir o sistema processual regido pelo Código de Processo Civil de 1973 como um sistema basicamente "rígido", que não comportava expressamente, na maior parte das vezes, a flexibilização procedimental. Com isso se quer dizer que, fora das hipóteses de procedimentos especiais eleitas pelo legislador, não havia, no processo de

\footnotetext{
${ }^{4}$ Ver também WAMBIER, Luiz Rodrigues. Abuso do procedimento especial. Revista de Processo, São Paulo, v. 204/2012, fev. 2012, p. 51-73.
} 
conhecimento, disposições que pudessem sugerir maiores adaptações do procedimento. Havia apenas algumas regras que, pontualmente, permitiam certas alterações. É o caso, por exemplo, do art. 333, parágrafo único, do $\mathrm{CPC} / 73$, que autorizava a distribuição consensual do ônus da prova sempre que a causa versasse direito disponível e não acarretasse excessiva dificuldade de provar para alguma das partes.

Mas, em geral, se se tratasse de matéria que não se encaixasse em qualquer dos procedimentos especiais, o procedimento comum é que deveria ser adotado, não havendo grande margem para adaptações.

Apesar da ausência de regra expressa, há quem defenda que, na vigência daquele Código, já era possível a flexibilização do procedimento por força do art. $5^{\circ}{ }^{\circ}, \mathrm{XXXV}$, da CF. Para esses autores, a garantia de prestação jurisdicional justa implicaria na possibilidade de adequação do procedimento para ajustá-la às particularidades da causa. Nesse sentido, é a doutrina de Eduardo Cambi e Aline Regina das Neves ${ }^{5}$, para quem:

A ausência de expressa previsão legal do princípio da adaptação do procedimento à causa não impede a sua aplicação, pois, como ele decorre da garantia constitucional do acesso à ordem jurídica justa, o ordenamento processual tem que ser interpretado conforme os postulados da unidade e da coerência.

O postulado da unidade do ordenamento jurídico exige do intérprete o relacionamento entre a parte e o todo mediante o emprego das categorias de ordem e unidade, enquanto o postulado da coerência impõe a obrigação de relacionar as normas com as outras normas que lhe são formal e materialmente superiores. (...)

A possibilidade de flexibilização procedimental independe de positivação expressa, porque decorre diretamente do acesso à ordem jurídica justa (art. 5. ${ }^{\circ}, \mathrm{XXXV}, \mathrm{CF} / 1988$ ), que, por ser uma garantia fundamental, irradia por todo o ordenamento jurídico.

\footnotetext{
${ }^{5}$ CAMBI, Eduardo; NEVES, Aline Regina das. Flexibilização procedimental no novo Código de Processo Civil. Revista de Direito Privado, São Paulo, v. 64/2015, out./dez. 2015, p. 219-259.
} 
De fato, a possibilidade de flexibilização procedimental decorre da interpretação do conceito amplo da garantia do acesso à justiça, que adiante será exposto. Porém, é certo que isso somente ficou claro com o Código de Processo Civil de 2015, que trouxe interessantíssimas e inovadoras disposições nesse sentido.

O novo Código não apenas explicitou uma possibilidade que já decorria do texto constitucional, como também a aprofundou e a intensificou, o que certamente traz, como proposto na exposição de motivos do Projeto preparado pela Comissão de Juristas disso encarregada pelo Senado Federal, imensa simplificação do sistema, com resultados positivos que contribuirão para a almejada efetividade do processo.

Na verdade, o procedimento padrão, estabelecido em lei, nem sempre se apresenta como o mais apropriado ao caso concreto. Afinal, não se pode exigir que o legislador consiga estabelecer regras únicas perfeitamente satisfatórias a todas as espécies de conflitos de interesses levados a julgamento pelo Poder Judiciário, e que ao mesmo tempo atende às peculiaridades de cada situação de direito material. Há situações em que o procedimento deve ser adaptado às singularidades do caso, visando a que a tutela jurisdicional seja prestada com maior qualidade e eficiência.

Mauro Cappelletti e Bryant Garth ${ }^{6}$ já há muito afirmavam a necessidade de se pensar o processo civil contemporâneo sob outro ponto de vista. No entender dos autores:

O enfoque sobre o acesso - o modo pelo qual os direitos se tornam efetivos - também caracteriza crescentemente o estudo do moderno processo civil. A discussão teórica, por exemplo, das várias regras do processo civil e de como elas podem ser manipuladas em várias situações hipotéticas pode ser instrutiva, mas, sob essas descrições neutras, costuma ocultar-se o modelo frequentemente irreal de duas (ou mais) partes em igualdade de condições perante a corte, limitadas apenas pelos argumentos jurídicos que os experientes advogados possam alinhar. O processo, no entanto, não deveria ser colocado no vácuo. Os juristas precisam, agora, reconhecer que as técnicas processuais servem a funções sociais (...). O "acesso" não é apenas um direito social fundamenta, crescentemente

\footnotetext{
${ }^{6}$ CAPPELLETTI, Mauro; GARTH, Bryant. Acesso à justiça. Porto Alegre: Fabris, 1988, p. 12-13.
} 
Revista Eletrônica de Direito Processual - REDP.

Rio de Janeiro. Ano 11. Volume 18. Número 3. Setembro a Dezembro de 2017

Periódico Quadrimestral da Pós-Graduação Stricto Sensu em Direito Processual da UERJ

Patrono: José Carlos Barbosa Moreira. ISSN 1982-7636. pp. 238-255

www.redp.uerj.br

reconhecido; ele é, também, necessariamente, o ponto central da moderna processualística. Seu estudo pressupõe um alargamento e aprofundamento dos objetivos e métodos da moderna ciência jurídica.

O acesso à justiça concretiza-se no acesso a uma ordem jurídica justa, concepção da mais profunda complexidade. A mera possibilidade de se submeter um conflito ao Poder Judiciário através do ajuizamento de uma ação é insuficiente quando se tem em mente o real alcance da garantia do acesso à justiça. $\mathrm{O}$ direito fundamental de acesso à justiça, previsto no art. 5. ${ }^{\circ}, \mathrm{XXXV}$, da $\mathrm{CF}$, pressupõe o direito de se obter uma tutela jurisdicional adequada, justa, efetiva e em tempo razoável.

A explicitação da possibilidade de flexibilização procedimental e o aprofundamento que a ela é dado vêm como instrumentos para a concretização do acesso à justiça, no contexto de que acima se tratou. E ela não propicia apenas que o procedimento seja adequado às singularidades da causa, como também possibilita a dispensa de atos processuais que se mostrarem desnecessários, trazendo inúmeros benefícios para a celeridade processual.

\section{Aspectos práticos da flexibilização procedimental no novo CPC}

O CPC/2015 contém dispositivos disposições que autorizam a flexibilização procedimental. Optou-se por tratar, neste breve espaço, de apenas alguns deles.

$\mathrm{O}$ art. $139^{7}$, por exemplo, que tutela os deveres do juiz, traz regras mais abrangentes do que aquelas que constavam no art. 125 do código revogado ${ }^{8}$. Dentre elas,

\footnotetext{
${ }^{7}$ Art. 139. O juiz dirigirá o processo conforme as disposições deste Código, incumbindo-lhe: I - assegurar às partes igualdade de tratamento; II - velar pela duração razoável do processo; III - prevenir ou reprimir qualquer ato contrário à dignidade da justiça e indeferir postulações meramente protelatórias; IV - determinar todas as medidas indutivas, coercitivas, mandamentais ou sub-rogatórias necessárias para assegurar o cumprimento de ordem judicial, inclusive nas ações que tenham por objeto prestação pecuniária; V promover, a qualquer tempo, a autocomposição, preferencialmente com auxílio de conciliadores e mediadores judiciais; VI - dilatar os prazos processuais e alterar a ordem de produção dos meios de prova, adequando-os às necessidades do conflito de modo a conferir maior efetividade à tutela do direito; VII exercer o poder de polícia, requisitando, quando necessário, força policial, além da segurança interna dos fóruns e tribunais; VIII - determinar, a qualquer tempo, o comparecimento pessoal das partes, para inquiri-las sobre os fatos da causa, hipótese em que não incidirá a pena de confesso; IX - determinar o suprimento de
} 
Revista Eletrônica de Direito Processual - REDP.

Rio de Janeiro. Ano 11. Volume 18. Número 3. Setembro a Dezembro de 2017

Periódico Quadrimestral da Pós-Graduação Stricto Sensu em Direito Processual da UERJ

Patrono: José Carlos Barbosa Moreira. ISSN 1982-7636. pp. 238-255

www.redp.uerj.br

destaca-se a que autoriza o juiz dilatar prazos processuais e alterar a ordem de produção dos meios de prova para adequá-los às necessidades do conflito. O escopo dessa norma, conforme expressamente prevê o dispositivo, é "conferir maior efetividade à tutela do direito".

Trata-se de regra coerente com a necessidade de se dar ao procedimento maior flexibilidade, de modo a que dele se extraia o melhor resultado. Mas a dilação dos prazos deverá observar a isonomia e obedecer a critérios de razoabilidade, de modo a ser determinada se e quando, em situações específicas, apresentar-se vantajosa para o efetivo alcance do objeto do processo.

A alteração da ordem de produção dos meios de prova poderá ocorrer, também excepcionalmente, quando a manutenção da ordem clássica puder ser prejudicial à sua própria produção. Trata-se de regra fundamentada na necessidade de se conferir ao processo a necessária racionalidade.

$\mathrm{O}$ art. $373^{9}$, ao dispor sobre o ônus da prova, prevê, como no sistema revogado e, aliás, segundo regra clássica, que ao autor incumbe provar o fato constitutivo de seu direito, enquanto que ao réu incumbe a prova da existência de fato que se possa opor como impeditivo, modificativo ou extintivo do direito afirmado pelo autor. Essa é a regra tradicional de distribuição do ônus da prova, que permanece sendo a regra geral no sistema

pressupostos processuais e o saneamento de outros vícios processuais; X - quando se deparar com diversas demandas individuais repetitivas, oficiar o Ministério Público, a Defensoria Pública e, na medida do possível, outros legitimados a que se referem o art. 5o da Lei no 7.347, de 24 de julho de 1985, e o art. 82 da Lei no 8.078, de 11 de setembro de 1990, para, se for o caso, promover a propositura da ação coletiva respectiva. Parágrafo único. A dilação de prazos prevista no inciso VI somente pode ser determinada antes de encerrado o prazo regular.

8 Art. 125. O juiz dirigirá o processo conforme as disposições deste Código, competindo-lhe: I - assegurar às partes igualdade de tratamento; II - velar pela rápida solução do litígio; III - prevenir ou reprimir qualquer ato contrário à dignidade da Justiça; IV - tentar, a qualquer tempo, conciliar as partes.

${ }^{9}$ Art. 373. O ônus da prova incumbe: I - ao autor, quanto ao fato constitutivo de seu direito; II - ao réu, quanto à existência de fato impeditivo, modificativo ou extintivo do direito do autor. $\S 1^{\circ}$ Nos casos previstos em lei ou diante de peculiaridades da causa relacionadas à impossibilidade ou à excessiva dificuldade de cumprir o encargo nos termos do caput ou à maior facilidade de obtenção da prova do fato contrário, poderá o juiz atribuir o ônus da prova de modo diverso, desde que o faça por decisão fundamentada, caso em que deverá dar à parte a oportunidade de se desincumbir do ônus que lhe foi atribuído. $\S 2^{\circ} \mathrm{A}$ decisão prevista no $\S 1^{\circ}$ deste artigo não pode gerar situação em que a desincumbência do encargo pela parte seja impossível ou excessivamente difícil. $\S 3^{\circ}$ A distribuição diversa do ônus da prova também pode ocorrer por convenção das partes, salvo quando: I - recair sobre direito indisponível da parte;

II - tornar excessivamente difícil a uma parte o exercício do direito. $\S 4^{\circ}$ A convenção de que trata o $\S 3^{\circ}$ pode ser celebrada antes ou durante o processo. 
Revista Eletrônica de Direito Processual - REDP.

Rio de Janeiro. Ano 11. Volume 18. Número 3. Setembro a Dezembro de 2017

Periódico Quadrimestral da Pós-Graduação Stricto Sensu em Direito Processual da UERJ

Patrono: José Carlos Barbosa Moreira. ISSN 1982-7636. pp. 238-255

www.redp.uerj.br

processual vigente. A inovação introduzida pelo CPC/2015 consiste naquilo que a doutrina chama de distribuição dinâmica do ônus da prova.

O parágrafo primeiro permite a atribuição do ônus de provar de modo diverso quando houver impossibilidade ou excepcional dificuldade no cumprimento do encargo ou, ainda, se se mostrar mais fácil a obtenção de prova do fato contrário. A distribuição diversa do ônus da prova também pode ocorrer por convenção das partes, conforme dispõe o parágrafo terceiro, nos moldes do que já ocorria na vigência do Código anterior, isto é, excepcionando-se as hipóteses de se tratar de prova que envolva direito indisponível da parte ou que torne excessivamente difícil o exercício do direito de provar.

$\mathrm{O}$ art. $190^{10}$, com nítida inspiração na arbitragem, avança ainda mais ao permitir que as partes celebrem negócio jurídico processual antes ou durante o processo, alterando as regras do procedimento, desde que se trate de direitos que admitam autocomposição. Há, no art. 190, a previsão de uma cláusula geral de negociação, consistente na possibilidade de alterações no procedimento se houver consenso entre juiz e partes, com o objetivo de "ajustá-lo às especificidades da causa".

Conforme esse dispositivo, pode haver negociação a respeito de ônus, poderes, faculdades e deveres processuais, por via contratual, previamente à existência do processo, ainda que de contrato de adesão se trate.

E o legislador de 2015, atento ao risco de abuso nesse tipo de negociação, introduziu no art. 190 um parágrafo único, que dispõe ser dever do juiz o controle da validade dessas convenções, que não deverão ser aplicadas se houver nulidade, quando inseridas de modo abusivo em contratos de adesão ou, ainda, quando alguma das partes estiver em manifesta posição de vulnerabilidade.

Outro dispositivo cuja leitura é fundamental é o art. $191^{11}$ que, igualmente inspirado no procedimento arbitral, autoriza partes e juiz a fixarem calendário para a

\footnotetext{
${ }^{10}$ Art. 190. Versando o processo sobre direitos que admitam autocomposição, é lícito às partes plenamente capazes estipular mudanças no procedimento para ajustá-lo às especificidades da causa e convencionar sobre os seus ônus, poderes, faculdades e deveres processuais, antes ou durante o processo. Parágrafo único. De ofício ou a requerimento, o juiz controlará a validade das convenções previstas neste artigo, recusando-lhes aplicação somente nos casos de nulidade ou de inserção abusiva em contrato de adesão ou em que alguma parte se encontre em manifesta situação de vulnerabilidade.

${ }^{11}$ Art. 191. De comum acordo, o juiz e as partes podem fixar calendário para a prática dos atos processuais, quando for o caso. $\S 1^{\circ} \mathrm{O}$ calendário vincula as partes e o juiz, e os prazos nele previstos somente serão modificados em casos excepcionais, devidamente justificados. $\S 2^{\circ}$ Dispensa-se a intimação das partes para a prática de ato processual ou a realização de audiência cujas datas tiverem sido designadas no calendário.
} 
prática dos atos processuais. Trata-se de dispositivo que também representa um grande avanço do sistema processual. Uma vez que o calendário seja respeitado pelas partes e pelo juiz, que a ele estarão vinculados (como expressamente prevê o § $1 .^{\circ}$ do art. 191), garantida estará a razoável duração do processo, assim como a previsibilidade, elemento integrante do conceito de segurança jurídica.

E há, ainda, a regra prevista no $\S 2 .^{\circ}$ do mesmo artigo, que determina que, tendo havido a fixação de calendário processual, dispensam-se todas as intimações das partes para a prática de atos processuais ou para a realização de audiências, cujas datas tenham sido previamente estabelecidas. A supressão de diversos atos de comunicação, além de simplificar o procedimento, possibilita a redução dos gastos de recursos públicos com o processo. $^{12}$

\section{O devido processo legal e a segurança jurídica}

Apesar de todos os efeitos positivos que a técnica de flexibilização procedimental é capaz de trazer para a efetividade e celeridade do processo, essas regras foram alvo de inúmeras críticas na doutrina.

Há quem afirme que a adaptação do procedimento acarreta ofensa ao devido processo legal. ${ }^{13}$ Esse posicionamento, a nosso ver, não parece ser o mais adequado. A garantia do devido processo legal não pode ser estática. $\mathrm{O}$ direito deve atender à dinamicidade da vida e das relações sociais. ${ }^{14}$

Se antes primava-se pela legalidade das formas, de modo que o devido processo legal pressupunha a obediência à rígida ao modelo predefinido em lei, hoje, é preciso desvincular-se essa garantia de seu caráter estritamente formal, pois sua concretização é permeada por outros fatores. A rigor, cumpre o postulado do devido processo legal o processo em que a tutela jurisdicional é prestada de forma adequada, justa, efetiva e no

\footnotetext{
${ }^{12}$ Sobre o tema, cf. WAMBIER, Luiz Rodrigues; BASILIO, Ana Tereza. O negócio processual: inovação do novo CPC. Migalhas. Disponível em: [http://www.migalhas.com.br/dePeso/16,MI228542,31047O+negocio+processual+Inovacao+do+Novo+CPC].

${ }^{13}$ Cf. BRAGHITTONI, Rogério Ives. Devido processo legal e direito ao procedimento adequado. Revista de Processo, São Paulo, v. 89/1998, jan./mar. 1998, p. 220-229. A respeito, v. também DINAMARCO, Cândido Rangel. A instrumentalidade do processo. 5. ed. São Paulo, Malheiros, p. 127.

${ }^{14}$ Sobre o assunto, ver WAMBIER, Luiz Rodrigues. Anotações sobre o princípio do devido processo legal. Revista de Processo, v. 63/1991, set. 1991, p. 54-63.
} 
Revista Eletrônica de Direito Processual - REDP.

Rio de Janeiro. Ano 11. Volume 18. Número 3. Setembro a Dezembro de 2017

Periódico Quadrimestral da Pós-Graduação Stricto Sensu em Direito Processual da UERJ

Patrono: José Carlos Barbosa Moreira. ISSN 1982-7636. pp. 238-255

www.redp.uerj.br

menor tempo possível, com a observância das garantias processuais constitucionais. Pressupõe procedimento adequado, frente às circunstâncias do conflito de interesses submetido a exame judicial. Com o passar dos anos, entendeu-se que o processo não pode ser um fim em si mesmo, e que é preferível um procedimento atípico, mas que seja capaz de proporcionar aos jurisdicionados a prestação de tutela adequada.

Grosso modo, o procedimento legitima-se pela obediência às garantias processuais fundamentais, entre as quais o contraditório, a ampla defesa e a isonomia. Desde que observadas essas garantias, não há que se falar em ofensa ao devido processo tão somente pela não submissão à forma padrão. Vale dizer, o juiz tem o dever de amoldar o procedimento às circunstâncias do caso concreto, quando se fizer necessário e sempre com a devida ponderação, em conformidade com o que dispõe o art. $8^{\circ}$ do CPC. Essa possibilidade torna o processo mais participativo, na medida em que conta com a ativa cooperação das partes e do juiz, visando a um tratamento mais adequado do que as opções hipoteticamente formadas pelo legislador. O mesmo se poderia dizer do contraditório e da ampla defesa. A flexibilização do procedimento não pode ser confundida com a mitigação dessas garantias. Pelo contrário, deve ser realizada com a estrita obediência a elas. ${ }^{15}$

$\mathrm{Na}$ doutrina, há ainda quem critique a possibilidade de adaptação do procedimento sob o argumento de que essa permissão ofenderia a segurança jurídica. ${ }^{16}$ Não há, todavia, relação direta entre a alteração do procedimento e a violação à segurança jurídica, até mesmo porque tal modificação depende da iniciativa das partes, cabendo ao juiz o dever de sempre fiscalizar as alterações propostas, controlando a validade e adequação dos acordos celebrados. Ou ainda, quando promovida de ofício, exige-se a prévia oportunização do contraditório. Portanto, o próprio exercício da autonomia da vontade e o dever de diálogo entre o juiz e as partes, somados à ampla concepção de acesso à justiça, conferem legitimidade à flexibilização do procedimento. ${ }^{17}$

\footnotetext{
${ }^{15}$ No mesmo sentido, ver BALEOTTI, Francisco Emilio. Poderes do juiz na adaptação do procedimento. Revista de Processo, v. 213/2012, nov. 2012, p. 389-408.

${ }^{16}$ Cf. BRAGHITTONI, Rogério Ives, op. cit.

${ }^{17}$ Eduardo Cambi e Aline Regina das Neves lecionam: "O princípio da adaptabilidade do procedimento à causa não se confunde com o sistema da liberdade das formas procedimentais nem redunda na anarquia procedimental, isto é, em um procedimento sem um arcabouço jurídico mínimo de formas capazes de assegurar o conhecimento prévio das regras do jogo. Apenas não refuta a possibilidade de que os sujeitos processuais - seja o juiz ou as partes - procedam a alterações recomendáveis, que vão desde a inversão da ordem de produção de provas, alteração de prazos legais, negócios jurídicos processuais, até a supressão de atos desnecessários ou inidôneos para o fim do processo. Tudo isso para a maior aderência entre o
} 
Revista Eletrônica de Direito Processual - REDP.

Rio de Janeiro. Ano 11. Volume 18. Número 3. Setembro a Dezembro de 2017

Periódico Quadrimestral da Pós-Graduação Stricto Sensu em Direito Processual da UERJ

Patrono: José Carlos Barbosa Moreira. ISSN 1982-7636. pp. 238-255

www.redp.uerj.br

\section{O modelo cooperativo de processo}

Superada a ideologia liberal do século XIX e a concepção do welfare state, o direito brasileiro, a exemplo de outros países como a Inglaterra, Portugal e França, tem tentado se moldar às novas reclamações de uma sociedade globalizada. ${ }^{18} \mathrm{O}$ novo código caminhou para uma melhor adequação do Direito Processual às exigências da sociedade contemporânea e ao Direito Constitucional, aprofundando e dando maior concretude a direitos e garantias processuais fundamentais. ${ }^{19} \mathrm{E}$ o momento atual demanda uma maior participação do juiz e também das partes, com a finalidade de assegurar, de maneira completa, a prestação da tutela jurisdicional.

Como já dito, a rigidez formal na condução do processo já não se mostra mais suficiente para lidar com os conflitos da atualidade.

Se antes o juiz assumia posição passiva em relação às partes, exige-se, agora, que ele aja ativamente para que o processo cumpra adequadamente sua função instrumental. ${ }^{20}$ É possível dizer que contraditório é a garantia de que haverá, entre juiz e partes, efetiva cooperação para que o processo alcance seus próprios objetivos, dentre os quais o da efetividade da jurisdição. Embora não se possa afirmar que a cooperação integra o contraditório, pode-se dizer, sem medo de errar, que se trata de princípios "coirmãos". ${ }^{21}$

procedimento adotado e a natureza e as particularidades da demanda, a possibilitar o desenvolvimento da criatividade dos sujeitos processuais sem prejudicar a efetivação da garantia constitucional de acesso à ordem jurídica justa" (CAMBI, Eduardo; NEVES, Aline Regina das, op, cit.). No mesmo sentido: "Para que as regras procedimentais tenham seu poder ordenador e organizador, coibindo o arbítrio judicial, para que promovam a igualdade das partes e emprestem maior eficiência ao processo, tudo com vistas a incentivar a justiça do provimento judicial, basta que sejam de conhecimento dos litigantes antes de sua implementação no curso do processo, sendo de pouca importância a fonte de onde provenham. Ou seja, sendo as variações rituais implementadas apenas após a participação das partes sobre elas em pleno contraditório, não se vê como a segurança jurídica seja abalada, já que o desenvolvimento do processo está sendo regrado e predeterminado judicialmente, o que o faz previsível" (GAJARDONI, Fernando da Fonseca. Flexibilização procedimental: um novo enfoque para o estudo do procedimento em matéria processual, de acordo com as recentes reformas do CPC. São Paulo: Atlas, 2008, p. 85).

${ }^{18}$ A respeito do tema, cf. ONO, Taynara Tiemi. A flexibilização procedimental: uma comparação entre os sistemas jurídicos brasileiro, inglês e português. Revista de Processo, v. 254/2016, abr. 2016, p. 407-427.

${ }^{19}$ Cf. PEIXOTO, Ravi. Rumo à construção de um processo cooperativo. Revista de Processo, São Paulo, v. 219/2013, mai. 2013, p. 89-114. Ver também: CAPELETTI, Mauro. Juízes legisladores?. Tradução de Carlos Alberto Alvaro de Oliveira. Sérgio Antonio Fabris Editor: Porto Alegre, 1999, p. 35-42.

${ }^{20}$ Cf. BALEOTTI, Francisco Emilio, op. cit.

21 Ver WAMBIER, Luiz Rodrigues. Notas sobre o contraditório no projeto do novo CPC. Migalhas. Disponível em:

[http://www.migalhas.com.br/dePeso/16,MI184362,81042- 
Revista Eletrônica de Direito Processual - REDP.

Rio de Janeiro. Ano 11. Volume 18. Número 3. Setembro a Dezembro de 2017

Periódico Quadrimestral da Pós-Graduação Stricto Sensu em Direito Processual da UERJ

Patrono: José Carlos Barbosa Moreira. ISSN 1982-7636. pp. 238-255

www.redp.uerj.br

Inserido no mesmo contexto das garantias de acesso à justiça, igualdade e ampla defesa, o contraditório desvincula-se da noção de mera ciência e reação e passa a representar também a oportunidade de plena participação e de efetiva influência na formação do convencimento do órgão julgador, observando-se, ainda, a paridade de tratamento. ${ }^{22}$

A partir do novo código, instituiu-se no sistema nacional um modelo cooperativo de processo. Com isso, não há mais espaço para protagonismos. As relações entre os

Notas+sobre+o+contraditorio+no+projeto+do+novo+CPC]. Ver também, Aspectos polêmicos da garantia constitucional do contraditório no novo CPC. Revista Paradigma, v. 25, p. 2-12, 2016.

22 A respeito, v. WAMBIER, Luiz Rodrigues; TALAMINI, Eduardo, op. cit., p. 76-77. A paridade de tratamento, todavia, não pode ser meramente formal. É preciso observar se as partes estão em situação de igualdade dentro do processo, concedendo-se a elas tratamento substancialmente igualitário. Para José Roberto dos Santos Bedaque, "O processo deve ser dotado de meios para promover a igualdade entre as partes. Um deles, sem dúvida, é a previsão de que o juiz participe efetivamente da produção da prova. Com tal atitude poderá evitar ele que eventuais desigualdades econômicas repercutam no resultado do processo. Essa interferência do magistrado não afeta de modo algum a liberdade das partes. Se o interesse controvertido incluir-se no rol dos chamados 'direitos disponíveis', permanecem elas com plenos poderes sobre a relação material, podendo, por exemplo, renunciar, desistir, transigir. Todavia, enquanto a solução estiver nas mãos do Estado, não pode o juiz contentar-se apenas com a atividade das partes. A visão do 'Estado-social' não admite essa posição passiva conformista, pautada por princípios essencialmente individualistas. Esse modo de analisar o fenômeno processual sobrepõe o interesse público do correto exercício da jurisdição ao interesse individual. Trata-se de visão essencialmente instrumentalista do processo. A real igualdade das partes no processo constitui valor a ser observado sempre, ainda que possa conflitar com outro princípio processual" (BEDAQUE, José Roberto dos Santos. Poderes instrutórios do juiz. 7. ed. São Paulo: RT, 2013, p. 107). E prossegue (p. 117): “Ademais, quando o juiz determina a realização de alguma prova, não tem condições de saber, de antemão, o resultado. O aumento do poder instrutório do julgador, na verdade, não favorece qualquer das partes. Apenas proporciona apuração mais completa dos fatos, permitindo que as normas de direito material sejam aplicadas corretamente. E tem mais: não seria parcial o juiz que, tendo o conhecimento de que a produção de determinada prova possibilitará o esclarecimento de um fato obscuro, deixe de fazê-lo e, com tal atitude, acabe beneficiando a parte que não tem razão? Para ele não deve importar quem seja o vencedor, autor ou réu. Fundamental, porém, seja a vitória atribuída àquele que efetivamente tenha razão, isto é, àquele cuja situação da vida esteja protegida pela norma de direito material, pois somente assim se pode falar que a atividade jurisdicional realizou plenamente sua função". No mesmo sentido, afirma Cândido Rangel Dinamarco que: "A visão tradicionalista do processo, com exagerado apego àquela ideia de um jogo em que cada um esgrima com as armas que tiver, levava à crença de que o juiz, ao tomar alguma iniciativa de prova, arriscar-se-ia temerariamente a perder a imparcialidade para julgar depois. Tal era o fundamento do princípio dispositivo, naquela visão clássica segundo a qual só as partes provariam e o juiz permaneceria sempre au-dessus de la mêlée, simplesmente recebendo as provas que elas trouxessem, para afinal examiná-las e valorá-las. Mas a vocação solidarista do Estado moderno (...) exige que o juiz seja um personagem participativo e responsável do drama judiciário, não mero figurante de uma comédia. Afinal, o processo é hoje encarado como um instrumento público que não pode ser regido exclusivamente pelos interesses, condutas e omissões dos litigantes - ele é uma instituição do Estado, não um negócio combinado em família (Liebman). Por tudo isso o princípio dispositivo vai sendo mitigado e a experiência mostra que o juiz moderno, suprindo deficiências probatórias do processo, não se desequilibra por isso e não se torna parcial. Isso não significa que o juiz assuma paternalmente a tutela da parte negligente. O que a garantia constitucional do contraditório lhe exige é que saia de uma postura de indiferença e, percebendo a possibilidade de alguma prova que as partes não requereram, tome a iniciativa que elas não tomaram e mande que a prova se produza" (DINAMARCO, Cândido Rangel. Instituições de Direito Processual Civil. 8. ed. São Paulo: Malheiros, 2016, v. 1, p. 353). 
sujeitos processuais, antes verticalizadas, agora, passam a ser horizontalizadas. Exige-se do juiz uma postura mais ativa frente às partes, impondo-se a ele e a essas o dever de mútua cooperação. E é nesse contexto que se insere a ampliação dos poderes do juiz e das partes para a adaptação do procedimento.

É esse o espírito do art. 6. ${ }^{\circ}$ do $\mathrm{CPC} / 2015$, segundo o qual "todos os sujeitos do processo devem cooperar entre si para que se obtenha, em tempo razoável, decisão de mérito justa e efetiva". E esse dever de diálogo abrange os deveres de esclarecimento, consulta, prevenção e auxílio. Compreende, além disso, a conduta ética (de boa-fé) de todos os envolvidos no processo, apesar do conflito de interesses.

O "dever de diálogo" do juiz com as partes também é destacado no art. 10 do CPC/2015. Conforme o dispositivo, nenhum órgão jurisdicional poderá decidir com base em fundamento de que não se tenha dado às partes conhecimento (direito à informação) e oportunidade de manifestação. $\mathrm{O}$ modelo cooperativo de processo não admite a prolação de decisão surpresa, ainda que de matéria de ordem pública se trate.

Essa nova ideologia também se reflete na introdução de uma metodologia de fundamentação das decisões, prevista no $\S 1 .^{\circ}$ do art. 489 do CPC, que, dentre outras disposições, impõe ao juiz o dever de "enfrentar todos os argumentos deduzidos no processo capazes de, em tese, infirmar a conclusão adotada pelo julgador” (inc. IV). Certamente, de nada adiantaria garantir às partes a oportunidade de participar e de influenciar a formação da convicção judicial se ao magistrado não se impusesse o dever de enfrentar todas as alegações relevantes aventadas no processo. Desse modo, ainda que seja a decisão ato exclusivo do juiz, no modelo cooperativo, ela deverá refletir o diálogo travado entre juiz e partes.

\section{Considerações finais}

A adaptação do procedimento não pode ser imponderada. Como regra geral, deve ser observado o padrão comum ou o procedimento dos especiais, se das respectivas hipóteses de aplicação se tratar. Para que a alteração seja legítima, exige-se que haja motivo concreto que a justifique. Daí a imprescindibilidade de que decisão judicial que a promover seja adequadamente fundamentada. 
Revista Eletrônica de Direito Processual - REDP.

Rio de Janeiro. Ano 11. Volume 18. Número 3. Setembro a Dezembro de 2017

Periódico Quadrimestral da Pós-Graduação Stricto Sensu em Direito Processual da UERJ

Patrono: José Carlos Barbosa Moreira. ISSN 1982-7636. pp. 238-255

www.redp.uerj.br

A doutrina ensina que a jurisdição deve ser compreendida não apenas como poder do juiz, mas como função estatal. ${ }^{23} \mathrm{O}$ novo Código de Processo Civil toma como inspiração o movimento do direito público em direção à participação ativa das partes, deixando em segundo plano a unilateralidade dos atos judiciais de apenas dizer o direito. A jurisdição, como componente do direito administrativo, passa a permitir um maior envolvimento do cidadão com as funções públicas. ${ }^{24}$ Incorpora-se, de maneira inovadora, a consensualidade no âmbito processual. ${ }^{25}$

É intuitivo que a adequação do procedimento ao caso concreto tende a dar ao rito maior eficiência, com possíveis bons resultados em termos de obtenção de frutos do processo mais rapidamente do que se fossem puramente aplicadas as regras do procedimento comum. Embora a celeridade não possa ser considerada um valor preponderante, é bem verdade que há situações em que a desejada efetividade está diretamente ligada ao tempo do processo.

A flexibilização das regras procedimentais tende a colaborar de modo decisivo para a melhor prestação da tutela jurisdicional. Será preciso, todavia, que se promova uma efetiva mudança na cultura processual, tanto no que diz respeito aos operadores do direito quanto em relação às próprias partes. Espera-se que, com esse modelo cooperativo mais flexibilizado, haja maior qualidade e resignação em relação às decisões judiciais, com significante redução da interposição de recursos e consecutiva diminuição de carga nos tribunais, aproveitando-se ao máximo as vantagens que o novo sistema proporciona.

\footnotetext{
${ }^{23}$ Assim entende THEODORO JÚNIOR, Humberto. Curso de direito processual civil. 56. ed. Rio de Janeiro: Forense, 2015, vol. 1, p. 106.

${ }^{24}$ A respeito do que denominou de "acordo de procedimento" e do calendário processual, o Relatório substitutivo da Câmara dos Deputados, p. 30, de relatoria-geral dos deputados Sérgio Barradas Carneiro e Paulo Teixeira, dispõe que: "Trata-se de importante acréscimo que vai ao encontro de ideia presente em várias passagens do projeto: ampliar a participação das partes no processo, favorecendo o desenvolvimento da noção de cidadania processual". Ainda (p. 31): "O enunciado ora proposto admite a adaptação procedimental, que não deve ser simplesmente proscrita. Mas a adaptação não é aceita aqui como resultado de um ato unilateral do juiz, e sim como fruto do consenso entre as partes e o julgador em situações excepcionais".

${ }^{25}$ Cf. ANDRADE, Érico. As novas perspectivas do gerenciamento e da "contratualização" do processo. Revista de Processo, São Paulo, v. 193/2011, mar. 2011, p. 167-200.
} 


\section{REFERÊNCIAS BIBLIOGRÁFICAS:}

ALVIM, Teresa Arruda. Nulidades do processo e da sentença. 7. ed. São Paulo: RT, 2014.

ANDRADE, Érico. As novas perspectivas do gerenciamento e da "contratualização" do processo. Revista de Processo, São Paulo, v. 193/2011, mar. 2011, p. 167-200.

BALEOTTI, Francisco Emilio. Poderes do juiz na adaptação do procedimento. Revista de Processo, v. 213/2012, nov. 2012, p. 389-408.

BEDAQUE, José Roberto dos Santos. Poderes instrutórios do juiz. 7. ed. São Paulo: RT, 2013.

BONÍCIO, Marcelo José Magalhães. Ensaio sobre o dever de colaboração das partes previsto no Projeto do novo Código de Processo Civil brasileiro. RePro 190/210.

BRAGHITTONI, Rogério Ives. Devido processo legal e direito ao procedimento adequado. Revista de Processo, São Paulo, v. 89/1998, jan./mar. 1998, p. 220-229.

CABRAL, Trícia Navarro Xavier. Poderes do juiz no novo CPC. RePro 208/275.

CAMBI, Eduardo. Neoconstitucionalismo e neoprocessualismo. São Paulo: RT, 2009.

; NEVES, Aline Regina das. Flexibilização procedimental no novo Código de Processo Civil. Revista de Direito Privado, São Paulo, v. 64/2015, out./dez. 2015, p. 219-259.

CAPELETTI, Mauro. Juízes legisladores?. Tradução de Carlos Alberto Alvaro de Oliveira. Sérgio Antonio Fabris Editor: Porto Alegre, 1999.

; GARTH, Bryant. Acesso à justiça. Porto Alegre: Fabris, 1988, p. 12-13.

CUNHA, Leonardo Carneiro da. A previsão do princípio da eficiência no projeto do novo Código de Processo Civil brasileiro. RePro 233/65.

DIDIER JR., Fredie. Fundamentos do princípio da cooperação no direito processual civil português. Coimbra: Wolter Klumers, 2010.

DINAMARCO, Cândido Rangel. A instrumentalidade do processo. 5. ed. São Paulo, Malheiros, p. 127. . Instituições de Direito Processual Civil. 8. ed. São Paulo: Malheiros, 2016, v. 1.

GAJARDONI, Fernando da Fonseca. Flexibilização procedimental: um novo enfoque para o estudo do procedimento em matéria processual, de acordo com as recentes reformas do CPC. São Paulo: Atlas, 2008. 
MOREIRA, José Carlos Barbosa. A constitucionalização do processo no direito brasileiro. In: MAC-GREGOR, Eduardo Ferrer; LARREA, Arturo Zaldívar Lelo de (coords.). Estudos de direito processual constitucional: homenagem brasileira a Héctor FixZamudio em seus 50 anos como pesquisador do direito. São Paulo: Malheiros, 2009. . Por um processo socialmente efetivo. In: Temas de direito processual. 8. ed. São Paulo: Saraiva, 2004.

. Sobre a "participação" do juiz no processo civil. In: GRINOVER, Ada Pellegrini; DINAMARCO, Cândido Rangel; WATANABE, Kazuo (coords.). Participação $e$ processo. São Paulo: RT, 1988.

OLIVEIRA, Carlos Alberto Alvaro de. Do formalismo no processo civil. São Paulo: Saraiva, 1997.

ONO, Taynara Tiemi. A flexibilização procedimental: uma comparação entre os sistemas jurídicos brasileiro, inglês e português. Revista de Processo, v. 254/2016, abr. 2016, p. 407-427.

PEIXOTO, Ravi. Rumo à construção de um processo cooperativo. Revista de Processo, São Paulo, v. 219/2013, mai. 2013, p. 89-114

REDONDO, Bruno Garcia. Devido processo "legal” e flexibilização do procedimento pelo juiz e pelas partes. Revista Dialética de Direito Processual 130/9.

SILVA, Paulo Eduardo Alves da. Gerenciamento de processos judiciais. São Paulo: Saraiva, 2010.

THEODORO JÚNIOR, Humberto. Curso de direito processual civil. 56. ed. Rio de Janeiro: Forense, 2015, vol. 1.

WAMBIER, Luiz Rodrigues. Abuso do procedimento especial. Revista de Processo, São Paulo, v. 204/2012, fev. 2012, p. 51-73.

- Anotações sobre o princípio do devido processo legal. Revista de Processo, v. 63/1991, set. 1991, p. 54-63.

- Aspectos polêmicos da garantia constitucional do contraditório no novo CPC. Revista Paradigma, v. 25, p. 2-12, 2016.

; TALAMINI, Eduardo. Curso Avançado de Processo Civil. 16. ed. São Paulo: Revista dos Tribunais, 2016, v. 1.

Liquidação da sentença civil: individual e coletiva. 5. ed. São Paulo: RT, 2013. 
Revista Eletrônica de Direito Processual - REDP.

Rio de Janeiro. Ano 11. Volume 18. Número 3. Setembro a Dezembro de 2017

Periódico Quadrimestral da Pós-Graduação Stricto Sensu em Direito Processual da UERJ

Patrono: José Carlos Barbosa Moreira. ISSN 1982-7636. pp. 238-255

www.redp.uerj.br

. Notas sobre o contraditório no projeto do novo CPC. Migalhas. Disponível em:

[http://www.migalhas.com.br/dePeso/16,MI184362,81042-

Notas+sobre+o+contraditorio+no+projeto+do+novo+CPC].

; BASILIO, Ana Tereza. O negócio processual: inovação do novo CPC. Migalhas.

Disponível em: [http://www.migalhas.com.br/dePeso/16,MI228542,31047-

$\mathrm{O}+$ negocio+processual+Inovacao+do+Novo+CPC] 